\title{
The Role of Oral Corrective Feedback Types in the Acquisition of the Grammatical Structures
}

\author{
Firoozeh Abedini ${ }^{1} \&$ Mohammadtaghi Shahnazari ${ }^{1}$ \\ ${ }^{1}$ Department of English, Faculty of Foreign Languages, University of Isfahan, Iran \\ Correspondence: Mohammadtaghi Shahnazari, Department of English, Faculty of Foreign Languages, \\ University of Isfahan, Iran. Tel: 98-313-793-4217. E-mail: m_t_shah@yahoo.com
}

Received: March 16, 2016 Accepted: April 6, 2016 Online Published: May 25, 2016

doi:10.5539/ijel.v6n3p127 URL: http://dx.doi.org/10.5539/ijel.v6n3p127

\begin{abstract}
This study investigated whether the effects of different types of corrective feedback (CF) (simple clarification request, enhanced prompt and elliptical elicitation) would differ on the acquisition of different types of grammatical structures. The target grammatical structures were verb endings (morphological morphemes) in three different English tenses including the simple present third person singular "-s", the present continuous verb formation marker "-ing", and the simple past verb ending" -ed". These targets were chosen because they are rather problematic for EFL learners to acquire. For this purpose, $31 \mathrm{~L} 1$ Persian EFL learners at intermediate level were given an opportunity to carry out some tasks and were provided with different types of CF on their erroneous utterances. Data analysis on the output accuracy following feedback on the three grammatical targets showed that the proportion of errors corrected in response to CF in the form of enhanced prompt was more than the proportion of errors corrected in response to the other two types of CF. These results suggest that the more explicit the $\mathrm{CF}$, the more effective it would be in correcting language learners' erroneous utterances regardless of the type of given grammatical structure.
\end{abstract}

Keywords: corrective feedback, elliptical elicitation, recasts, enhanced prompt, modified output

\section{Introduction}

CF has been defined differentially by different scholars. Ellis (2006) has defined it as "responses to learner's utterances containing an error"; also Chaudron (1988) has taken it as a "complex phenomenon with several functions". According to Leeman (2003), feedback acts as a mechanism by which language learners are provided with some evidence. This evidence can be either positive or negative. Positive evidence comprises information which illustrates that a phenomenon is possible in a given language and negative evidence, on the other hand, is information which illustrates what is not acceptable in the target language. Negative evidence might be of two kinds, direct or indirect. Direct negative evidence comes from the correction of the learner's error by other language speakers; it can be called the corrective feedback, oral or written. However, indirect negative evidence is seen when certain structures do not occur in a language.

Corrective feedback (CF) has been the focus of attention in the area of second language acquisition (SLA) over the last two decades. A great number of studies indicates that corrective feedback plays a vital role in L2 growth (Leeman, 2003; Lyster \& Mori, 2006; Lyster \& Ranta, 1997; McDonough, 2005; Nassaji, 2007; Nassaji, 2009). Some of these studies are experimental and were carried out in the laboratory context (Doughty \& Varela, 1998; Lyster, 2004), and some others are observational and were conducted in the classroom context (e.g., Lyster \& Ranta, 1997).

All these studies suggest that CF plays a significant role in second language development (e.g., Sheen, 2004). For instance, research suggests that the way L2 learners respond to the given feedback foreshadows the learners L2 development; however, it is not yet clear that how SLA is associated with learners' responses to the provided feedback.

Despite these studies; however, it is not yet entirely known whether different types of CF would have a similar effect in the acquisition of different linguistic targets. More specifically, the effectiveness of different types of corrective feedback may differ from one linguistic item to another in the same linguistic category such as grammar. In prior studies, researchers focused on the effect of typically one type of CF on a particular linguistic 
item under different situations using different methodologies and materials which in turn may explain variations in the results.

All these point to the need for further research to examine the effects of different types of CF on different types of linguistic targets using the same materials and methodologies. To find the answer to this question, in the current study, three types of CF including simple clarification request, elliptical elicitation and enhanced prompt were chosen because they are consistent in the process in that L2 learners are pushed to produce output. This process might be a variable which could be well controlled by the researchers. It should be noted that recasts, as a type of CF, was not chosen because here someone like a researcher reformulates L2 learners' erroneous utterances into a more target like form, and the L2 learners do not have any productions and may just confirm the reformulation by repeating it. Thus, to keep consistency and have more reliable results, three types of CF in the form of elicitation were selected.

The linguistic targets chosen for the purpose of this study included three English tenses which are quite problematic for EFL learners; namely, simple present, simple past and present continuous tense. More specifically, using the correct form of verb in these tenses is problematic for EFL learners. They usually drop the third person singular "-s", misuse past marker "-ed", or the present participle verb formation marker "-ing".

Thus, this study was designed to examine whether different types of CF would impact differentially on the acquisition of different grammatical targets. If so, which type of CF would lead to more successful acquisition of L2 targets and production of modified output? This study also sought to explore the L2 learners' attitudes towards each type of CF.

\section{Review of Literature}

Some researchers believe that interaction paves the ground for language learning. For example, in interaction hypothesis, Long argues that a combination of input, output, corrective feedback and selective attention takes place in teacher-learner or learner-learner interactions. He believes that in such interactions, CF plays an important role in L2 development. This is because these interactions involve negotiation of meaning along with $\mathrm{CF}$ on incomprehensible messages and erroneous utterances which could in turn result in L2 learning (Gass, 1997; Long 1996). This could be done through providing an opportunity for learners to understand the form that matches with their intention through conversational interaction (e.g., Doughty, 2001; Gass, 1997). Since attention is a key factor for learning to occur, CF makes learning easier by drawing the learners' attention to the non-target like forms and encouraging them to modify their erroneous utterances (Schmidt, 1995). Depending on the situation in which the verbal interaction takes place; CF might be presented explicitly-explicit correction or explaining the linguistic rule — or implicitly—clarification request and recasts. Whether provided implicitly or explicitly, CF may be categorized based on the source of the error correction, either by others or self-correction (e.g., Scheglof, Jefferson, \& Sacks, 1997). The error correction provided to the learner by others may be in the form of reformulation, explicit correction, or meta-linguistic error correction. However, self-correction may take place in the form of elicitations where learners are pushed to rephrase their erroneous utterances. This process may lead to producing pushed output as well. Overall, all types of CF may contribute to language acquisition. A large number of researchers have examined the contribution of each type of CF. They all believe in the effectiveness of interactional feedback; however, they debate on the degree of effectiveness of different types of CF (Doughty, 2001; Lyster, 1998, 2004; Lyster \& Ranta 1997).

$\mathrm{CF}$ in the form of reformulation can be effective by providing the learners with negative or positive evidence. Gass (1997) proposed that through language learning process, learners may be provided with two types of input: positive evidence and negative evidence. Correct utterances a learner may be exposed to are considered as positive evidence. In contrast, the negative evidence is observed when the learner is informed about the errors made in the target language output by CF. In other words, negative evidence is realized when the CF is provided in response to the learner's incorrect L2 production. Thus, CF may help language development by providing negative evidence.

Some prior studies revealed the beneficial effects of recasts (e.g., Ellis, 2001; Macky \& Philip, 1998), and some others show that CF in the form of elicitation leads to a better language learning (e.g., Lyster, 2004; Lyster \& Ranta, 1997). In the area of corrective feedback research, different researchers have achieved different conclusions, and these differences may be due to the research settings and conditions (e.g., Lyster \& Mori, 2006) These different claims on the effectiveness of CF have drawn many researchers' attention to investigate more about the role of CF in L2 learning (e.g., Lyster, 2004). While a great number of researchers have been trying to find out whether CF can assist L2 development, there is still no clear-cut conclusion revealing which type of CF could be more effective and which one could be less. 
Recently, a growing body of research has focused on different facets of CF, and different researchers have debated over its effectiveness in L2 acquisition. Lyster, Saito and Sato (2013) have investigated some related issues such as CF effectiveness, CF preferences, CF frequency and some theoretical perspectives in support of $\mathrm{CF}$. They found that learners express an extreme favor towards CF, but depending on learners' cultural backgrounds, learning experiences, and proficiency level, this preference may vary from one learner to another.

Also, some taxonomies have been proposed by some of these scholars (e.g., Nassaji, 2007; Nassaji, 2009; Lyster \& Ranta, 1997). One of these taxonomies has been proposed by Lyster and Ranta (1997) in which there are two broad categories: Reformulation which can be divided into recasts and explicit correction, and prompts which can be divided into elicitation, meta-linguistic clues, clarification requests, and repetition. Nassaji (2009) provided another classification in which he renamed the prompts as elicitations. In his classification, prompts are referred to the additional information provided to the learner in order to make the CF more explicit.

A great number of scholars have investigated the learners' responses to the different types of CF (e.g., Doughty 1994; Lyster \& Ranta, 1997). Some of these studies were conducted in immersion classes (e.g., Lyster \& Ranta, 1997) and some of them were done in ESL/EFL classes (e.g., Sheen, 2004). Lyster \& Ranta (1997) divided learners' responses into two categories: the responses which are still in need of repair and those that don't need repair anymore.

Prior studies revealed advantages and disadvantages of different types of CF. For example some studies showed that recasts as a type of CF could be problematic because learners may miss them while interacting due to their implicitness and their similarity to other types of classroom discourse (Lyster, 1998); however, they are beneficial because they do not interrupt the interaction and they rely on learners' errors (e.g., Long \& Robinson, 1998). In addition, the teachers use them frequently in meaning focused classroom interaction (Ellis et al., 2001a).

In one study, Leowen \& Philp (2006) investigated the effectiveness of recasts on L2 development. Their study revealed that recasts were significantly as beneficial as other types of provided feedback; however, repair following recasts did not forecast the correct production in the post test. In the same line, some scholars (e.g., Doughty \& Varela, 1998) have found some empirical support in the effectiveness of recasts. They showed that providing the learners with recasts could be more effective than giving no feedback. In another study, Mackey \& Philp (1998) found out that recasts had a positive effect in learning high stages of question forms comparing with other types of implicit feedback.

Further supports come from lots of studies conducted in the laboratory settings. These studies have scrutinized the role of recasts in L2 development (e.g., Mackey \& Philip 1998) and mostly are used as evidence in support of the effectiveness of recasts in different reviews (e.g., Long, 2007; Gass, 2010). In contrast, while some studies suggest that meta-linguistic feedback can be more effective (Carroll \& Swain, 1993), other studies (e.g., Lyster, 2004) found that prompts can be more effective than all other types of feedback.

Adherents of different types of CF make their own arguments to support their claims. For example, one group argues that recasts play a vital role because they provide negative evidence without interrupting the interaction and make the learners interact even if they lack some linguistic knowledge, while prompts and explicit correction cause hindering in acquisition because of interrupting the flow of communication, so, they could be less effective (Long, 2007). On the other hand, theorists of socio-cultural theory (Aljaafreh \& Lantolf, 1994) and output hypothesis (Swain, 1985) and skill acquisition theory (Anderson, 1980) are in support of the effectiveness of the prompts which aim to elicit the correct form and mostly led to self-repair. All these contrasting findings point to the need for further research in this area.

Research on error correction following CF types suggests that different types of CF could lead to L2 development in various ways. For example, learners who have some knowledge about the target form make better use of recasts comparing with those who have zero knowledge about the target form (e.g., Mackey \& Philp 1998). In addition to laboratory studies, a great number of studies have focused on the impact of different CF Types on L2 development in the classroom setting (e.g., Lyster, 2004). Lightbown (2008) believes that using various types of $\mathrm{CF}$ would be more effective than using only one type, and maybe this is why it is impossible to identify the most effective type of CF. Moreover, it cannot be guaranteed that one kind of CF would be efficient for all types of linguistic features (Sheen, 2011).

As it is obvious from the literature review, knowledge on the effectiveness of different types of CF on different linguistic targets along with learners' attitudes and preferences for a particular CF type is limited. To fill this gap and enrich the literature, the present study was designed with the following research questions. More specifically, this study sought to explore which type of corrective feedback is more effective to learn different L2 
grammatical targets. To meet this end, three different types of CF including simple clarification request, elliptical elicitation, and enhanced prompt were used to address three different grammatical targets including the simple present third person singular "-s", the present continuous verb formation marker "-ing", and the simple past verb ending" -ed".

1) What type of corrective feedback leads to more successful learning of the three grammatical targets (third person singular"-s", present continuous tense, and irregular past tense" ed")?

2) Are there any differences in the extent of production of modified output following different types of elicitations?

3) What is the learners' attitude towards each type of CF?

\section{Method}

\subsection{Participants}

31 L1 Persian EFL learners at intermediate level participated in this study. They included 26 females and 6 males and their ages ranged from 15 to 35 years $(M=21.22)$. The participants had an average period of nearly two years in learning English. Their participation in the study was voluntary. The reason for choosing this level was that the learners, certainly, had learned the aimed grammatical structures, so that they could produce them during performing the tasks.

In order to make sure about the participants' proficiency level a proficiency test (Top Notch Proficiency Test) was administered. It contained 120 questions evaluating participants' general language knowledge.

\subsection{Materials}

The present research is a quasi-experimental study which involves comparing the treatment group performance before and after being given CF. The independent variables are three different types of CF (i.e., elliptical, enhanced prompt, and simple clarification request) and the dependent variables are the acquisition of three different grammatical structures (the simple present third person singular "-s", the present continuous verb formation marker "-ing", and the simple past verb ending" -ed".).

To collect the data, the researchers first made sure that all the participants were at the intermediate proficiency level. Then a treatment and post-treatment session were held outside the classroom in their free time, and everything was audio-recorded. The tasks used were 9 pictorial description tasks ( 3 tasks for each grammatical structure, each task involved 6 related pictures depicting a particular scene of an event in one of the aimed tenses). In the first session, each participant was asked to describe the pictures. Before, describing the pictures, the researcher gave a prompt for each task and provided each participant with one of the three CF types when language errors were made. The participants were asked to describe the tasks randomly based on the aimed structures (i.e. not describing the tasks related to the present continuous tense first and then tasks related to irregular past tense and so on). There were also two distractors involving the use of comparative forms and use of quantitative adjectives such as a little, a few, and a lot of. The tasks and distracters were randomly set and given to the participants. During describing the pictures, the researcher provided the participant with different types of CF and everything was recorded by the researcher, so that she could have the details of the interaction The researcher did her best to use different types of corrective feedback equally across different types of targets.

In the post-test session, immediately after the treatment, the participants were asked again to describe the pictures, but they were not provided with any kind of CF this time. This was to see whether CF had been influential in learning grammatical targets. Their output was also recorded here.

After collecting the exchanges between the researchers and participants, they were fully transcribed and checked against the audio recordings by the researchers. Then they were analyzed for each participant separately in order to see how each type of CF worked for each of these grammatical structures. The first type of CF was simple clarification request which aimed to elicit reformulation implicitly (1). The second type of CF was elliptical elicitation which elicited the correct form by repeating the utterance up to the error and waiting for the learner to supply the correct form (Nassaji, 2007) (2). The third type of CF used in this study was enhanced prompt which elicited a reformulation with additional explicit metalinguistic prompts that indicated more explicitly to the learner that something was wrong with the utterance (Nassaji, 2007) (3). Here are some examples from the data:

(1) Learner: She taking photo .

Researcher: Sorry...? (Simple clarification request)

Learner: She's taking... 
(2) Learner: He listen to the music every day.

Researcher: He...? (Elliptical elicitation)

Learner: He listens to the music.

(3) Learner: He getting on the airplane.

Researcher: He getting on the airplane? Is that correct? (Enhanced prompt)

Learner: He is getting on the airplane

\section{Results}

The total number of the provided CF was calculated. Altogether, 314 feedback opportunities had been given, out of which $126(40 \%)$ were related to simple present tense, $72(23 \%)$ were related to simple past tense, and $116(37 \%)$ were related to present continuous tense. And out of 314 erroneous utterances, $78(25 \%)$ were followed by simple clarification request, 99 (32\%) were followed by enhanced prompt, and $137(43 \%)$ were followed by elliptical elicitation. Table 1 summarizes the descriptive statistics for different types of CF.

Table 1. Total number and percentage for each type of corrective feedback

\begin{tabular}{lll}
\hline CF Type & n & $\mathbf{\%}$ \\
\hline Clarification Request & 78 & 25 \\
Enhanced Prompt & 99 & 32 \\
Elliptical Elicitation & 137 & 43 \\
\hline Total & 314 & 100 \\
\hline
\end{tabular}

In the case of simple present tense, $126(40 \%) \mathrm{CF}$ was provided out of which $28(9 \%)$ were clarification request, $42(13 \%)$ were enhanced prompt, and $56(18 \%)$ were elliptical elicitation. The erroneous utterances related to past tense received (72) $23 \%$ of the total corrective feedback, out of which $7 \%$ (21) were clarification request, $4 \%$ (12) were enhanced prompt, and 12\% (39) were elliptical elicitation. Of the total CF opportunities, 116 (37\%) were given for the present continuous related errors out of which $29(9 \%)$ were clarification request, $45(15 \%)$ were enhanced prompt, and $42(13 \%)$ were elliptical elicitation. These results suggest that although a major amount of total CF was of elliptical elicitation, enhanced prompt was the most effective kind of CF in consolidation of the explicit knowledge of three target tenses. Table 2 displays the distribution of the feedback opportunities which led to modified output and $+/$ - repair across different types of CF.

Table 2. Modified output and immediate repair in response to subtypes of elicitation

\begin{tabular}{llllllllll}
\hline & \multicolumn{2}{l}{ Total CF Types } & \multicolumn{2}{l}{ Modified Output } & \multicolumn{2}{l}{ Repair } & \multicolumn{2}{c}{ No Repair } \\
\hline & $\mathrm{n}$ & $\%$ & $\mathrm{n}$ & $\%$ & $\mathrm{n}$ & $\%$ & $\mathrm{n}$ & $\%$ \\
A. & Simple Present Tense & & & & & & & & \\
& Clarification Request & 28 & 9 & 12 & 6 & 8 & 5 & 4 & 9 \\
& $\begin{array}{l}\text { Enhanced Prompt } \\
\text { Elliptical Elicitation }\end{array}$ & 42 & 13 & 25 & 13 & 18 & 13 & 7 & 16 \\
B. & Simple Past Tense & & & 32 & 17 & 22 & 15 & 10 & 23 \\
& Clarification Request & 21 & 7 & 14 & 7 & 11 & 8 & 3 & 7 \\
& Enhanced Prompt & 12 & 4 & 7 & 4 & 6 & 4 & 1 & 2 \\
& Elliptical Elicitation & 39 & 12 & 25 & 13 & 20 & 14 & 5 & 11 \\
C. & Present Continuous Tense & & & & & & & & \\
& Clarification Request & 29 & 9 & 16 & 9 & 12 & 8 & 4 & 9 \\
& Enhanced Prompt & 45 & 15 & 32 & 17 & 28 & 19 & 4 & 9 \\
& Elliptical elicitation & 42 & 13 & 27 & 14 & 21 & 14 & 6 & 14 \\
\hline & 314 & 100 & 190 & 100 & 146 & 100 & 4 & 100 \\
\hline
\end{tabular}

\section{Discussion}

This study examined the effect of different types of CF on different grammatical targets to see which one is more influential in correcting erroneous utterances and the extent to which the provision of each CF type may result in production of modified output which in turn facilitates second language leaning. 
Although a growing body of research have demonstrated that interactional feedback contributes to language acquisition in general, some studies argue that some kinds of feedback which push the learner to produce language may lead to a more significant effect on second language learning process (e.g., Doughty, 2001; Long \& Robinson, 1998; Swain, 1993) compared with those which just provide the learner with comprehensible input. Swain (1985) proposed in her Output Hypothesis that in order to develop learners' interlanguage, only providing them with input is not sufficient, but context of learning should be in such a way that the learners find some opportunities to produce output. This suggests that those types of CF which are characterized in the literature as prompt or as elicitation (Nassaji, 2009), a type of feedback pushing the learner to modify her non-target like utterance, may be more effective in language learning (e.g., Panova \& Lyster, 2002, Lyster, 2004). Based on this assumption, the current study focused on three types of feedback classified as elicitations. However, it should be noted that the mechanisms focusing only on the erroneous forms are more explicit and those mechanisms focusing not only on the form, but also on the meaning are more implicit, though some researchers prefer more explicit prompts in interlanguage development (e.g., Havranek, 2002). The current study aimed to investigate the effect of three types of feedback in the form of elicitation (simple clarification request, enhanced prompt and elliptical elicitation), on the acquisition of three grammatical structures (i.e., third person singular "s", present continuous tense "ing", and irregular past tense" -ed").

The first research question sought to find out the most effective CF type in the acquisition of each of the target structures. The findings of this research suggest that the three types of elicitations made a good contribution to learning the tenses, but the extent of learning following each type of elicitation was not the same. The rate of post-treatment correction for enhanced prompt was higher than elliptical elicitation followed by clarification request.

As the results display, CF in the form of Enhanced Prompt had the most significant impact on the acquisition of the targets, while simple clarification form had the least effect. $40 \%$ of the total provided CF in treatment session was related to simple present tense errors, $23 \%$ was related to simple past tense and $37 \%$ was related to present continuous.

In the case of simple present tense, simple clarification request, enhanced prompt, and elliptical elicitation covered $9 \%, 13 \%$ and $18 \%$ proportion of the total feedback respectively. Considering the repairs following each type of elicitation, enhanced prompt was the most effective type of elicitation and clarification request was the least effective type in the learning of simple past tense. The proportion of $23 \%$ feedback provided to the errors was related to simple past tense. As the results indicated, again enhanced prompt was the most effective type of $\mathrm{CF}$ followed by elliptical elicitation and simple clarification request. And finally, present continuous tense errors received the proportion of $37 \%$ of the total CF types. This proportion covered $9 \%, 13 \%$ and $15 \%$ of the total CF types for clarification request, enhanced prompt and elliptical elicitation respectively. The rate of correction as a result of feedback in the form of enhanced prompt was more than that of correction of other types of elicitation.

Overall, these results suggest that enhanced prompt, as the most explicit CF type made a greater contribution to learning of grammatical structures. One explanation for these results may reside in the explicitness of the elicitation in the form of enhanced prompt, because participants provided with enhanced prompt paid more attention to their erroneous utterances, and this attention may facilitate the cognitive process of L2 development. So, while CF plays a key role in L2 development in general, providing the learners with more explicit CF types leads to more successful language learning.

This finding goes in line with that of some other researches that showed more explicit CF types draw the learners' attention more and thus are more effective in learning, though the investigated CF types in those studies were different from the CF types investigated in the present study. As it was noted earlier, some of the researchers investigating the effectiveness of different types of CF in general believe that those types of CF that provide opportunities for pushed output and make the learners produce the language would have a more permanent effect on the learners than those that just reformulate the non-target like utterance into a target like one (Swain, 1993). Swain claimed that learners have linguistic knowledge in general, but they should be given some opportunities that enable them to make use of their language resources, so that they may notice their lack of linguistic knowledge on a particular language item (e.g., Doughty, 2001; Swain, 1993; Williams, 2005). These opportunities make the learners notice the gap (Swain, 1998; Williams, 2005) between their own language and target language given (Swain, 1993). So, as it is clear, all the three CF types investigated in the current study were in the form of elicitation, so the difference between them lies in the level of explicitness. So, significant effect of Enhanced Prompt relies on its explicitness. Overall, the findings suggest that Enhanced Prompt was the most effective type of prompt due to its explicitness. The results of the current study provide further support for those of previous studies (e.g., Carroll \& Swain, 1993), but are inconsistent with the finding of some prior 
studies (Leeman, 2003). In addition, the results bear out that Clarification Request had the least effect on the acquisition of the targets in this study which is in line with the results of prior research (e.g., Nobuyoshi and R. Ellis 1993).

Enhanced prompt also led to more successful language learning compared with elliptical elicitation. One reason for this may reside in the ambiguity that elliptical elicitation caused. More specifically, the participants did not get the aim of repetition of their utterance up to the erroneous part; rather they thought that the researcher asked them to repeat their utterance.

Concerning the second research question, it should be noted that in the case of simple present tense, elliptical elicitation led to the most proportion of modified output (MO) followed by enhanced prompt, and finally clarification request resulted in the lowest proportion of MO. The amount of MO in response to the CF (elliptical elicitation) on simple past tense was the highest. Finally, the least proportion of MO belonged to enhanced prompt. And finally in the case of present continuous, the highest rate belonged to enhanced prompt followed by elliptical elicitation. These results suggest that $\mathrm{CF}$ could lead to the production of MO which in turn may result in Language learning.

In this study, some of the participants were reluctant to take part in the oral interview (Appendix A), maybe because they were afraid of committing errors while speaking in the target language, and this could arouse anxiety in those participants. Anxiety can be one of the factors that may affect language learning. So this anxiety may affect their language production following CF types, especially elliptical elicitation, because it was more ambiguous comparing with enhanced prompt. Ambiguity of elliptical elicitation along with the participant's anxiety led them not to pay attention to the error correction and they just reacted to the corrective feedback without thinking.

To answer the third research question, the researcher asked the participants' ideas about the ways they were provided with feedback after they did the tasks. $80 \%$ of the participants preferred enhanced prompt over two other sorts of elicitations. They believed that this type of elicitation had created a more positive attitude in them. Also some of them claimed that elliptical elicitation was ambiguous. They said that they misinterpreted the researcher, and they thought that the researcher meant to draw their attention to their errors in the use of gender pronouns rather than the tense errors. $7 \%$ of the participants preferred elliptical elicitation because they claimed that it drew their attention to the form. Other $23 \%$ of the participants claimed that it doesn't make any differences to be provided with any types of elicitation.

So considering the participants' explanations to the third question, it sounds like that CF should be given as explicitly as possible because it can lead to more L2 development. However, the participants' level of proficiency should be taken into consideration. Because despite less proficient learners who prefer more explicit $\mathrm{CF}$ types, more proficient learners may prefer more implicit $\mathrm{CF}$ types.

\section{Conclusion}

In summary, the results of the current study suggest that while CF in the form of elicitations (prompts in Lyster's term) may be more effective than CF in the form of reformulation subtypes (e.g., Doughty, 2001; Long \& Robinson, 1998; Swain, 1993), explicitness of different elicitation forms plays a vital role in the amount of their effectiveness. The findings showed that the most explicit form of elicitation, i.e. enhanced prompt, made a greater contribution to language learning (because it led to more repairs), but the most ambiguous form led not to a significant amount of repair. Overall, these findings support the idea that effectiveness of CF may rely on its explicitness.

Considering the amount of modified output, there were no clear results about the factors affecting the production of modified output in the learners' responses to the elicitation subtypes. And it shows the need for further research that considers the amount of modified output following elicitation subtypes more cautiously.

Also, it was shown that learners preferred enhanced prompt over other two elicitation subtypes because of its explicitness, though clarification request was identified as the most ambiguous form of elicitation subtypes. Overall, this study suggests that the explicit forms of CF could more result in L2 learning than the implicit forms of CF.

\section{References}

Aljaafreh, A., \& Lantolf, J. (1994). Negative feedback as regulation and second language learning in the zone of proximal development. The Modern Language Journal, 78(4), 465-483. http://dx.doi.org/10.1111/j.1540-4781.1994.tb02064.x 
Carroll, S., \& Swain, M. (1993). Explicit and implicit negative feedback: An empirical Study of the learning of linguistic generalizations. Studies in Second Language Acquisition, 5, 357-386. http://dx.doi.org/10.1017/S0272263100012158

Chaudron, C. (1988). Second language classrooms. Cambridge: Cambridge University Press. http://dx.doi.org/10.1017/CBO9781139524469

Doughty, C. (2001). Cognitive underpinning of focus on form. In P. Robinson (Ed.), Cognition and second language instruction (pp. 206-257). Cambridge: Cambridge University Press. http://dx.doi.org/10.1017/CBO9781139524780.010

Doughty, C., \& Varela, E. (1998). Communicative focus on form. In C. Doughty \& J. Williams (Eds.), Focus on form in classroom second language acquisition (pp. 114-138). Cambridge: Cambridge University Press.

Ellis, R. (2008). The Study of Second Language Acquisition (2nd ed.). Oxford: Oxford University Press.

Gass, S. (2010). Interactionist perspectives on second language acquisition. In R. Kaplan (Ed.), The Oxford handbook of applied linguistics (pp. 217-231). Oxford: Oxford University Press. http://dx.doi.org/10.1093/oxfordhb/9780195384253.013.0015

Havranek, G. (2002). When is corrective feedback most likely to succeed? International Journal of Educational research, 37, 255-270. http://dx.doi.org/10.1016/S0883-0355(03)00004-1

Leeman, J. (2003). Recasts and second language development: Beyond negative evidence. Studies in Second Language Acquisition, 25, 37-63. http://dx.doi.org/10.1017/s0272263103000020

Lightbown, P. (2008a). Transfer appropriate processing as amodel for class second language acquisition. In Z. Han (Ed.), Understanding second language process (pp. 27-44). Clevedon, UK: Multilingual Matters.

Loewen, S., \& Philp, J. (2006). Recasts in adults English L2 classrooms: Characteristics, explicitness, and effectiveness. Modern Language Journal, 90, 536-556. http://dx.doi.org/10.1111/j.1540-4781.2006.00465.x

Long, M. (2007). Problems in SLA. Mahwah, NJ: Lawrence Erlbaum.

Long, M., \& Robinson, P. (1998). Focus on form: Theory, research and practice. In C. Doughty \& J. Williams (Eds.), Focus on form in classroom language acquisition (pp. 15-41). Cambridge: Cambridge University Press.

Lyster, R. (1998). Negotiation of form, recasts, and explicit correction in relation to error types and learner repair in immersion classrooms. Language Learning, 48, 183-218. http://dx.doi.org/10.1111/1467-9922.00039

Lyster, R. (1998). Recasts, repetition, and ambiguity in L2 classroom discourse. Studies in Second Language Acquisition, 20, 51-81. http://dx.doi.org/10.1017/S027226319800103X

Lyster, R. (2004). Differential effects of prompts and recasts in form-focused instruction. Studies in Second Language Acquisition, 26, 399-432. http://dx.doi.org/10.1017/s0272263104263021

Lyster, R., \& Mori, H. (2006). Interactional feedback and instructional counterbalance. Studies in Second Language Acquisition, 28, 269-300. http://dx.doi.org/10.1017/s0272263106060128

Lyster, R., \& Ranta, L. (1997). Corrective feedback and learner uptake: Negotiation of form in communicative classrooms. Studies in Second Language Acquisition, 19, 37-66. http://dx.doi.org/10.1017/s0272263197001034

Lyster, R., Saito, K., \& Sato, M. (2013). Oral corrective feedback in second language classrooms. Language Teaching, 46(1), 1-40. http://dx.doi.org/10.1017/S0261444812000365

Mackey, A., \& Philp, J. (1998). Conversational interaction and second language development: Recasts, responses, and red herrings? Modern Language Journal, 82, 338-356. http://dx.doi.org/10.1111/j.1540-4781.1998.tb01211.x

McDonough, K. (2005). Identifying the impact of negative feedback and learners' responses on ESL question development. Studies in Second Language Acquisition, 27, 79-103. http://dx.doi.org/10.1017/s0272263105050047

Nassaji, H. (2007). Elicitation and reformulation and their relationship with learner repair in dyadic interaction. Language Learning, 57, 511-548. http://dx.doi.org/10.1111/j.1467-9922.2007.00427.x

Nassaji, H. (2009). Effects of recasts and elicitations in dyadic interaction and the role of feedback explicitness. Language Learning, 59(2), 411-452. http://dx.doi.org/10.1111/j.1467-9922.2009.00511.x 
Nobuyoshi, J., \& Ellis, R. (1993). Focused communication tasks and second language acquisition. ELT Journal, 47, 113-128. http://dx.doi.org/10.1093/elt/47.3.203

Schmidt, R. (1995).Consciousness and foreign language learning: A tutorial on the role of attention and awareness in learning. In R. Schmidt (Ed.), Attention and awareness in foreign language learning (pp. 1-63). Honolulu, HI: University of Hawaii, Second Language Teaching and Curriculum Center.

Sheen, Y. (2004). Corrective feedback and learner uptake in communicative classrooms across instructional settings. Language Teaching Research, 8, 263-300. http://dx.doi.org/10.1191/1362168804lr146oa

Sheen, Y. (2011). Corrective feedback, individual differences and second language learning. New York: Springer. http://dx.doi.org/10.1007/978-94-007-0548-7

Swain, M. (1985). Communicative competence: Some roles of comprehensible input and comprehensible output in its development. In S. Gass \& C. Madden (Eds.), Input in second language acquisition (pp. 235-253). Rowley, MA: Newbury House.

Swain, M. (1993). The output hypothesis: Just speaking and writing aren’t enough. Canadian Modern Language Review, 50, 158-164.

Swain, M. (1998). Focus on form through conscious reflection. In C. Doughty \& J. Williams (Eds.), Focus on form in classroom second language acquisition (pp. 64-81).Cambridge: Cambridge University Press.

Williams, J. (2005). Form-focused instruction. In E. Hinkel (Ed.), Handbook on research in second language teaching and learning (pp. 673-691). Mahwah, NJ: Lawrence Erlbaum.

\section{Appendix A. Questions Used in the Interview}

The questions used in the interview are as follow:

1. Were you able to distinguish between three different types of corrective feedback?

2. Which type of corrective feedback do you prefer?

3. What's the reason for your preference?

\section{Copyrights}

Copyright for this article is retained by the author(s), with first publication rights granted to the journal.

This is an open-access article distributed under the terms and conditions of the Creative Commons Attribution license (http://creativecommons.org/licenses/by/3.0/). 